\author{
Proceedings of the $10^{\text {th }}$ International Conference on Applied Informatics \\ Eger, Hungary, January 30-February 1, 2017. pp. 103-110 \\ doi: $10.14794 /$ ICAI.10.2017.103
}

\title{
Use of statistical software for experimental design
}

\author{
Lôrinc Garai \\ Doctoral School of Multidisciplinary Engineering Sciences, Széchenyi University \\ garailorinc@garailorinc.hu
}

\begin{abstract}
Experimental design and evaluation of an analytical method was performed with Statistica and Minitab statistical software.

Instrumental analysis (chromatography) of vitamin E was optimized. During the test, vitamin $\mathrm{E}$ is separated from the fatty part of food by saponification. The time and temperature of this step is critical. A Hungarian standard describing the protocol (MSZ-EN 12822) recommends a wide range of temperature and time, giving an opportunity to optimize the recovery of the analyte.

Experimental tests were performed from vegetable oil sample to find the temperature and time settings for the best recovery. Both factors were examined with centered two-level factorial design. Trend analysis showed a tendency towards the corner points of highest possible temperature and shortest possible saponification time. Evaluation was made with Statistica and Minitab.
\end{abstract}

Keywords: statistical software, experimental design, Statistica, Minitab

$M S C: 62 \mathrm{~K} 15$

\section{Introduction}

Vitamin and mineral intake in adequate doses are needed for health (see [1]) and balanced nutrition (see [2]). Among fat soluble vitamins, Vitamin E protects polyunsaturated fatty acids and membrane lipids against oxidation (see [3]), and has an anti-inflammatory effect (see [4]). Nowadays, vitamin intake is covered partially by supplementation. To assure the correct dosage, fat soluble vitamins and their concentrations in different food matrixes are to be determined. High Performance Liquid Chromatography (HPLC) is a common method for the analysis of vitamin E in vegetable oil samples. ISO standard MSZ-EN 12822:2014 (further standard) (see [5]) defines the methods of direct extraction and of saponification 
in the preparation of fatty samples for HPLC. According to standards, the method of direct extraction requires no heating, assuring the full recovery of heat sensitive vitamin E (see [6]). This method is compatible with Normal Phase High Performance Liquid Chromatography (NP-HPLC) since fatty samples can be dissolved in apolar solvents and are directly injected to the chromatograph. Drawbacks of direct extraction are:

- Limit of Detection (LOD) is high: due to the high lipid content the sample can hardly be concentrated.

- Reversed Phase Liquid Chromatography (RP-HPLC) commonly used in laboratories poses difficulties: a switch, if needed, to NP-HPLC requires thorough washing of the tubing even if it is time and solvent consuming. Instead, a switch to another RP-HPLC eluent would be more simple. Further, RPHPLC compatible solvents (e.g. methanol, acetonitrile) are not applicable for fatty samples' direct extraction.

The method of saponification is another way of fatty sample preparation for HPLC analysis of vitamin A [7]. In contrast to the method of direct extraction, samples for saponification can be concentrated. In foods containing vitamin A in native and/or esterified forms (e.g. acetate, palmitate), the method of saponification allows them to be measured jointly and no special reference material is required for measuring ester forms. Drawback of the method of saponification is the light and heat sensitivity of the analytes, conditions worth to consider (see [6]).

Compared to NP-HPLC systems, RP-HPLC systems are more common in use, consequently, the method of saponification is preferred. Regarding standard, two important factors, temperature and time of saponification are only given in ranges instead of exact settings. The goal of my work is to find optimum settings in time and temperature in the method of saponification.

For this purpose, two-factor, two-level, first and second degree statistical experimental design (SED) was introduced to optimize settings in time and temperature in the method of saponification.

Sample extracts were examined by RP-HPLC. Fatty samples were taken from vegetable oil brand 'Delma Joghurt' for measuring gamma tocopherol of Vitamin E.

Among several statistical software, Statsoft Statistica 13 (further Statistica 13) and Minitab 17.1 (further Minitab 17) were chosen for SED analysis. Statistica 13.0 (see [8]) and Minitab 17 (see [9])] are worldwide used by industrial customers and in the higher education (see [10]).

\section{Experiment}

\subsection{First degree SED}

For factor settings (Table 1), $2^{\mathrm{k}}$ SED was used, implying number 2 standing for factors levels (low and high) and power ' $\mathrm{k}$ ' standing for factors temperature $\left(\mathrm{T}\left[{ }^{\circ} \mathrm{C}\right]\right)$ 


\begin{tabular}{|c|c|c|}
\hline Levels/Factors & Temperature $\left[{ }^{\circ} \mathrm{C}\right]$ & Time $[\mathrm{min}]$ \\
\hline Lower level & 60 & 25 \\
\hline Upper level & 82 & 50 \\
\hline Center point & 71 & $35^{*}$ \\
\hline
\end{tabular}

Table 1: Vegetable oil sample saponification factors, two level, first degree SED

and time $(\mathrm{t}[\mathrm{min}])$.

* For technical reasons, center point was set to 35 min instead of 37.5 min (mean of lower and upper levels). This discrepancy can be ignored at SED analysis.

Initial experiments were made with first degree SED (see [10, 11], Table 1). Adequacy of the design was checked with center point settings. SEDs were generated and evaluated both with Statistica 13 and Minitab 17.

\subsection{Sample Preparation}

For the experiments, replicates were prepared as shown below in brief ([5]):

- 3-5 g of vegetable oil was weighed into a $250 \mathrm{ml}$ flask.

- $300 \mathrm{mg}$ of ascorbic acid was added.

- $50 \mathrm{ml}$ of ethanol, then $15 \mathrm{ml}$ of $50 \%$ potassium hydroxide was added.

- Saponification was performed under reflux cooler. Successful saponification was indicated by the disappearance of fatty drops.

- Sample was rinsed from flask with $50 \mathrm{ml}$ ethanol into a $250 \mathrm{ml}$ funnel.

- $120 \mathrm{ml}$ water was added (breaking emulsion), then extraction was made with 3 times $50 \mathrm{ml}$ hexane.

- Hexane phase was evaporated and the residue was dissolved in methanol for RP-HPLC test.

\section{Results}

\subsection{Results of vegetable oil sample first degree SED}

Table 2 shows the highest recovery of vitamin A achieved at temperature $82{ }^{\circ} \mathrm{C}$ and time $25 \mathrm{~min}$. 


\begin{tabular}{|c|c|c|}
\hline $\mathrm{T}\left[{ }^{\circ} \mathrm{C}\right]$ & $\mathrm{t}[\mathrm{min}]$ & Vitamin E $[\mathrm{mg} / 100 \mathrm{~g}]$ \\
\hline 60 & 35 & 54.1 \\
\hline 60 & 35 & 56.1 \\
\hline 60 & 65 & 45.9 \\
\hline 71 & 50 & 57.2 \\
\hline 71 & 50 & 56.7 \\
\hline 82 & 35 & 55.2 \\
\hline 82 & 35 & 55.7 \\
\hline 82 & 65 & 51.1 \\
\hline 82 & 65 & 48.3 \\
\hline
\end{tabular}

Table 2: Results of vegetable oil sample first degree SED

\subsection{Outline of result evaluation}

Evaluation with Statistica 13 and Minitab 17 happened as shown below (see [12, $13,14])$.

- Initial criterion for further evaluation was the normal distribution of residuals ${ }^{1}$.

- Adequacy of the SED was tested by comparing predicted and measured center point values.

- Main effects ${ }^{2}$ were defined.

- If SED had been adequate, response surface was plotted to visualize factor effects.

\subsection{Normal distribution of residuals}

Vitamin E showed even distribution of residuals. Normal distribution of residuals (normal probability plot for vitamin E) are shown in Figure 1 and Figure 2.

\subsection{Effect estimates}

Effect estimates for vitamin E (Figure 3) shows that SED curvature is not significant $(p=0.197>0.05)$, consequently, first degree statistical experimental model is adequate for vitamin $\mathrm{E}$.

Effect estimates for vitamin E generated by Minitab 17 confirm this adequacy (Figure 4). Similarly to Statistica 13 results, Minitab 17 shows non-significant SED curvature $(p=0.230>0.05)$.

\footnotetext{
${ }^{1}$ Residual: the term stands for the difference between measured and predicted values of dependent variable.

${ }^{2}$ Main effect: the term stands for the effect of one independent variable on dependent variable, ignoring the effects of all other independent variables.
} 


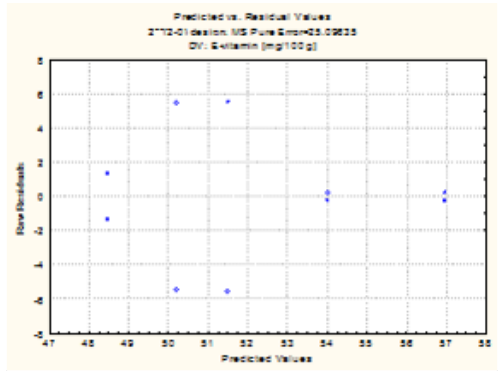

Figure 1: Distribution of residuals of vitamin E results

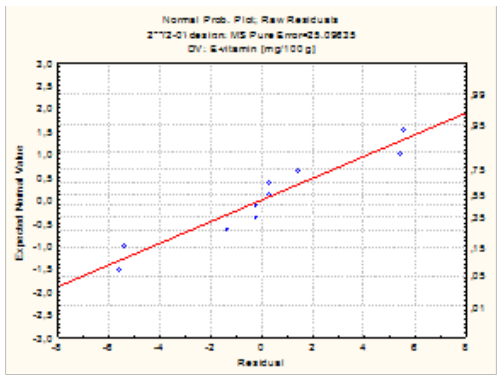

Figure 2: Normal probability plot for residuals of vitamin E results

\begin{tabular}{|c|c|c|c|c|c|c|c|c|c|c|}
\hline \multirow[b]{2}{*}{ Factor } & \multicolumn{10}{|c|}{$\begin{array}{l}\text { Effect Estimates; Var.:E-vitamin [mg/100 g]; R-sqr=,41264; Adj:0, (étolaj e-vitamin mod) } \\
2^{* *}(2-0) \text { design; MS Pure Error }=25,09635 \\
\text { DV: E-vitamin [mg/100 g] }\end{array}$} \\
\hline & Effect & $\begin{array}{l}\text { Std.Err. } \\
\text { Pure Err }\end{array}$ & $t(5)$ & $p$ & $\begin{array}{c}-95, \% \\
\text { Cnf.Limt }\end{array}$ & $\begin{array}{r}+95, \% \\
\text { Cnf.Limt }\end{array}$ & Coeff. & $\begin{array}{l}\text { Std.Err. } \\
\text { Coeff. }\end{array}$ & $\begin{array}{c}-95, \% \\
\text { Cnf.Limt }\end{array}$ & $\begin{array}{r}+95, \% \\
\text { Cnf.Limt }\end{array}$ \\
\hline Mean/Interc & 506 & 1,771170 & 28,8 & 0,000 & 46,4921 & 55,59799 & 51, & 1,771170 & 46,49212 & 55,59799 \\
\hline & 11,76912 & 913 & 1,4 & 0,1 & $-8,5922$ & 32,13047 & & 3, & $-4,29612$ & 6524 \\
\hline & 0,39671 & 2340 & 0,1 & 0,9 & $-8,7092$ & 9,50258 & 0,1 & 1,7 & $-4,35458$ & 4,75129 \\
\hline (2)t [min] & $-3,41757$ & 3,542340 & $-0,96478$ & 0,3 & $-12,5234$ & 5,68831 & $-1,7$ & 1,771170 & $-6,26172$ & 2,84415 \\
\hline 1 by 2 & $-2,13031$ & 3,542340 & $-0,60138$ & 0,573808 & $-11,2362$ & 6,97557 & $-1,06515$ & 1,771170 & $-5,61809$ & 3,48778 \\
\hline
\end{tabular}

Figure 3: Factorial effect estimates table - first degree SED by Statistica 13

In contrast, Pareto chart generated by Statistica 13 (Fig. 5) shows significance of curvature comparable with the main effects for vitamin E (see column 'Curvatr.', column '(2)t [min]', and column '(1) $\left.\mathrm{T}\left[{ }^{\circ} \mathrm{C}\right]^{\circ}\right)$.

Pareto chart of Minitab 17 (Fig. 6) does not include curvature. Figure 6 shows $\mathrm{p}$ values for temperature, for time of saponification and for curvature within the same range, confirming Pareto chart of Figure 5. This ambiguity can be resolved by further experiments with a second-degree SED (see: [14]. As performing further experiments was temporarily not poosible, response surfaces were plotted using results of first degree SED (Table 2). 


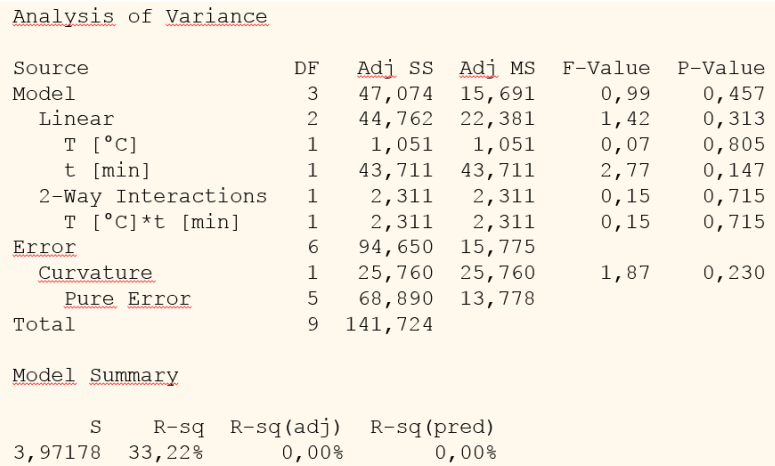

Figure 4: Factorial effect estimates table - first degree SED by Minitab 17

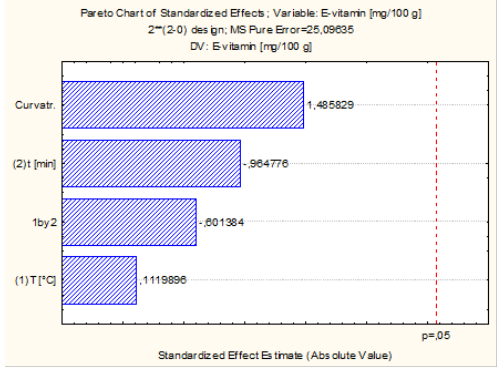

Figure 5: Vitamin E effects by Pareto chart - Statistica 13

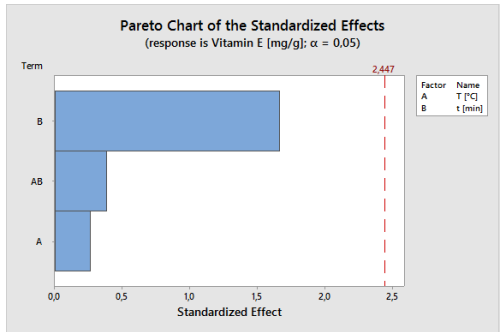

Figure 6: Vitamin E effects by Pareto chart - Minitab 17

\subsection{Surface diagrams}

Factor effects for vitamin E are visualized on Figure 7 and Figure 8.

The surface diagram shows an optimum segment at the shortest time and highest temperature of saponification in the recovery of vitamin E content. Saponifi- 


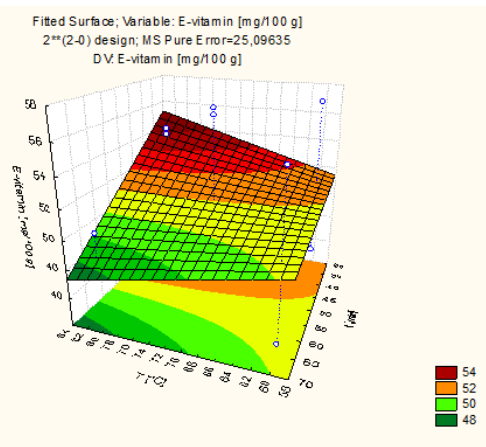

Figure 7: Response surface of Vitamin E content of vegetable oil samples (first degree SED) - Statistica 13

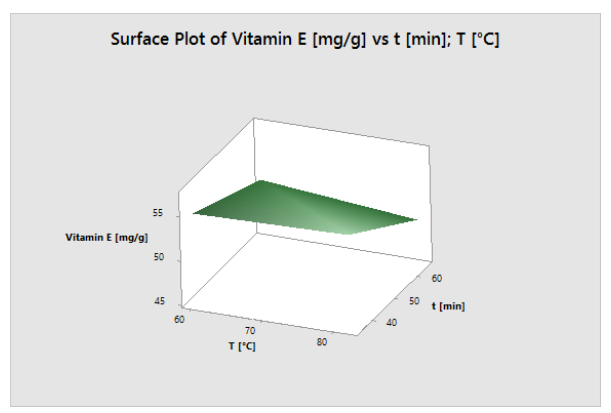

Figure 8: Response surface of Vitamin E content of vegetable oil samples (first degree SED) - Statistica 13

cation time $(\mathrm{t})$ and temperature $(\mathrm{T})$ settings for this segment are $t=25$ minutes and $T=82^{\circ} \mathrm{C}$. As $\mathrm{T}$ is at its applicable maximum and only $\mathrm{t}$ can be changed, further experiments were performed to shorten time of saponification. Thus optimal settings of saponification time and temperature were 18 minutes and $82{ }^{\circ} \mathrm{C}$, respectively.

\section{Concluding remarks}

Methods of saponification described in MSZ-EN 12822:2014 were optimized for time and temperature settings. For the optimization the idea of SED was created and introduced with the help of Statsoft Statistica 13 software and Minitab 17 software. Vegetable oil samples supplemented with vitamin E were used for testing SED introduced.

Initial experiments were performed using $2^{\mathrm{k}}$ first degree SED. Adequacy of this design was checked with center point settings. 
First degree SED was adequate in the recovery of vitamin E, giving an optimum in recovery at the highest temperature and shortest time of saponification. The optimum settings in saponification temperature and time are $82{ }^{\circ} \mathrm{C}$ and 18 minutes, respectively.

Statistica 13 and Minitab 17 both are to be used for SED analysis. Still, compared to Minitab 17 for response surfaces generated, Statistica 13 is highly recommended because of the ease at interpretation of the graph results.

Acknowledgements. Analytical laboratory resources were provided by Bálint Analitika Ltd.

\section{References}

[1] Reichrath J, Lehmann B, Carlberg C, Varani J, Zouboulis CC Vitamins as hormones, Horm. Metab. Res. Vol. 39 (2007), 71-87.

[2] Qi YJ, Niu QL, Zhu XL, Zhao XZ, Yang WW, Wang XJ Relationship between deficiencies in vitamin $\mathrm{A}$ and $\mathrm{E}$ and occurrence of infectious diseases among children, Eur. Rev. Med. Pharmacol Sci, Vol. 20 (2016), 5009-5012.

[3] Lucarini M., Pedulli G.F. Overview of Antioxidant Activity of Vitamin E The Encyclopedia of Vitamin E, (2007), 3-10.

[4] Borel P., Desmarchelier C. Genetic Variations Involved in Vitamin E Status, Int. J. Mol. Sci., Vol. 17 (1993)

[5] MSZ-EN 12822:2014 Foodstuffs - Determination of vitamin E by high performance liquid chromatography - Measurement of alfa-, beta- , gamma- and delta-tocopherol, 2014, Hungarian Standards Institution

[6] XU, Z. Comparison of extraction methods for quantifying vitamin E from animal tissues, Bioresource Technology, Vol. 99 (2008), 8705-8709

[7] Nollet L. M. L. Handbook of Food Analysis, Marcel Dekker Inc., New York, Vol. 1 (1996), 611-613

[8] LINK: https://www.featuredcustomers.com/vendor/statistica/customers (accessed: 03. 05. 2017)

[9] LiNK: https://www.minitab.com/en-us/company/customers (accessed: 03. 05. 2017)

[10] LiNK: http://www.statsoft.hu/references/refer_3.html\#Egyetem (accessed: 03. 05. 2017)

[11] LiNK: http://www.lkq.hu/ref0.htm (accessed: 03. 05. 2017)

[12] S. Kemeny, A. Deak Kísérletek tervezése és értékelése, Müszaki Könyvkiadó, (2000), 341-350

[13] Douglas C. Montgomery Introduction to statistical quality control, John Wiley E Sons Inc., Jefferson City, Vol. 13 (1993), 550-597

[14] S. Kemeny, A. Deak Kísérletek tervezése és értékelése, Múszaki Könyvkiadó, (2000), 376-381 